\title{
A PRÁtica de EDUCAÇÃo AMBIENTAL NO ÂMBITO DO ENSINO FORMAL: ESTUDOS PUBLICADOS EM REVISTAS ACADÊMICAS BRASILEIRAS
}

\author{
Patrícia de Lourdes Viegas ${ }^{1}$ \\ Zysman Neiman ${ }^{2}$
}

Resumo: Através de uma pesquisa descritiva-explicativa, com procedimentos bibliográficos, este estudo objetivou analisar práticas de EA desenvolvidas junto ao ensino formal, publicadas entre 2007 a 2012 em revistas acadêmicas. Utilizou-se o Método Análise de Conteúdo e a Estatística Descritiva para análises qualitativas e quantitativas, respectivamente. Os principais resultados foram: 1) as práticas apresentam o perfil que se resume a envolvimento de estudantes (baixíssima abrangência), de nível fundamental, desenvolvidas, por longo prazo, no espaço escolar através de pesquisadores e apoiadores; 2) aplicadas em instituições públicas do sudeste do país; 3) trabalham temas diversos, disciplinas não definidas, predominância da interdisciplinaridade, transversalidade e enfoque conteúdo-crítica-ação, e busca por significados de Meio Ambiente, utilizando técnicas diversas; 4) Baseiam-se em projetos, com estratégias, técnicas e processos de avaliação diversos. Este estudo configurou-se como pressuposto para avaliar o desenvolvimento da EA no contexto científico, além de ser parâmetro norteador a estudiosos que utilizam esse meio para divulgar estudos, aos que utilizam como referenciais e aos que avaliam submissão de artigos.

Palavras-chave: Educação Ambiental. Prática. Revistas Acadêmicas.

\section{THE PRACTICE OF ENVIRONMENTAL EDUCATION IN THE FORMAL EDUCATION: BRAZILIAN STUDIES PUBLISHED IN ACADEMIC JOURNALS}

Abstract: Through a descriptive-explanatory research with bibliographic procedures, this study aimed to analyze practices developed with Environmental Education to formal education, published between 2007-2012 in academic journals. We used the Method of Content Analysis and Descriptive Statistics for qualitative and quantitative analysis. The main results were: 1) practices have the following profile: student involvement (very low coverage), the fundamental level, developed for long term at school by researchers and supporters; 2) applied in public institutions in the country southeast;3) work various themes, subjects not defined, prevalence of interdisciplinary, crosscutting approach and content-critical-action, and search for meanings Environment using various techniques; 4) They are based on projects and strategies, and various assessment techniques. This study was configured as a prerequisite to assess the development of EA in a scientific context, besides being a guiding parameter to scholars who use this medium to promote studies, those using as benchmarks and evaluating article submission.

\footnotetext{
1 Mestre em Sustentabilidade na Gestão Ambiental pela Universidade Federal de São Carlos (UFSCar), Sorocaba, São Paulo, Brasil.

patriciaviegas@fasternet.com.br

${ }^{2}$ Doutor em Psicologia pela Universidade de São Paulo (USP). Professor Associado I na Universidade Federal de São Paulo (UNIFESP), Diadema, São Paulo, Brasil.

zneiman@gmail.com
} 
Keywords: Environmental Education. Practice. Academic Journals.

\section{LA PRÁCTICA DE LA EDUCACIÓN AMBIENTAL EN ÁMBITO EDUCACIÓN FORMAL: LOS ESTUDIOS PUBLICADOS EN REVISTAS ACADÉMICAS BRASILEÑAS}

Resumen: A través de una investigación descriptiva-explicativa con procedimientos bibliográficos, este estudio tuvo como objetivo analizar las prácticas de EA desarrolladas por la educación formal, publicadas entre 2007 a 2012 en revistas académicas. Se utilizó el análisis de contenido y el Método de Estadística Descriptiva para los análisis cualitativos y cuantitativos, respectivamente. Los principales resultados fueron: 1) las prácticas tienen el perfil que resume la participación de los estudiantes (muy baja cobertura), nivel elemental, desarrolladas, a largo plazo, en la escuela a través de los investigadores y apoyadores; 2) que se aplica en las instituciones públicas en el sureste; 3) trabajar varios temas, disciplinas que no se definen, enfoque predominantemente interdisciplinario intersectorial y la acción de contenido crítico, y la búsqueda de significados de Medio Ambiente utilizando diversas técnicas; 4) Se basan en proyectos, estrategias, técnicas y diversos procesos de evaluación. Este estudio se configura como una condición previa para evaluar el desarrollo de la EA en el contexto científico, además de ser un parámetro de guiar a los estudiosos que utilizan este medio para dar a conocer los estudios, a usar como puntos de referencia y la evaluación de la sumisión del artículo.

Palabras-llave: Educación ambiental. Práctica. Revistas Académicas.

\section{Introdução}

"A cartografia da produção brasileira em Educação Ambiental (EA) tem um significado digno de análise [...]" (REIGOTA, 2007, p. 57), conforme depoimento de vários especialistas que vêm participando de encontros nacionais e internacionais, no final do século XX o Brasil era considerado um dos países com maior variedade de experiências em EA, com iniciativas originais que, muitas vezes, se associam a intervenções na realidade local (BRASIL, 1997).

A EA vem sendo discutida, praticada, construída com diversos conceitos e abordagens, diferindo em si no caminho e na forma de se construir o processo educacional. $\mathrm{Se}$, outrora, tínhamos pouco acesso às publicações na área da EA, hoje uma vasta literatura nos impede de termos consciência das variadas experiências, pesquisas, vivências e referenciais teóricos tecidos na rede caleidoscópica dessa área. Sua heterodoxia é legada por diferentes formações, desde as ciências mais rígidas aos conhecimentos populares; da pesquisa acadêmica aos movimentos ecologistas; de estratégias de pura contemplação da natureza à ousadia de ações para uma participação mais democrática; de amplos conceitos que se misturam e se divorciam nos emaranhados fios, nós e elos tecidos dos caminhos multifacetados da EA (SATO; GAUTHIER; PARIGIPE, 2005).

No âmbito da EA, no ensino formal, muitos trabalhos têm sido publicados com o intuito de apresentar suas concepções, metodologias e resultados e, com isso, compartilhar a experiência com demais atuantes ou não da área. Entretanto, não muitas são as publicações que fazem uma análise dos trabalhos em si. Assim, o presente estudo teve como objetivo analisar as práticas de EA desenvolvidas junto ao ensino formal, publicadas no período compreendido entre 2007 a 2012 por meio de artigos em revistas acadêmicas que abordam, exclusivamente, a EA. De modo que identificamos e apresentamos, de uma maneira sintética, 
a produção do conhecimento em práticas de EA desenvolvidas junto as instituições de ensino, sob a visão das publicações acadêmicas, contribuindo para o universo de pesquisas voltadas à área em questão.

Diante de uma educação repleta de visões e abordagens, é necessário esclarecer em que conceito de EA este trabalho encontra-se pautado. Aqui, entende-se que a EA no âmbito escolar é um processo mediado pela realidade que envolve estudantes, professores, funcionários (comunidade escolar), familiares e comunidade do entorno da escola, no desenvolvimento da temática ambiental, objetivando propiciar aos envolvidos uma compreensão crítica das questões vinculadas ao tema, permitindo, assim, o desenvolvimento de valores e atitudes em prol das questões ambientais.

É necessário enfatizar que esta pesquisa, apesar de apresentar um perfil de mapeamento, não deve ser classificada como 'estado da arte'. Este ultrapassa um perfil inventariante, já que além de fornecer informações sobre os estudos, apresenta uma análise detalhada da produção dos mesmos, favorecendo a definição das bases em que a prática de EA junto ao ensino formal está construída nessas revistas acadêmicas.

\section{Procedimentos Metodológicos}

O enquadre metodológico deste trabalho pode ser descrito, quanto ao objetivo, como uma pesquisa descritiva-explicativa, e, quanto ao procedimento, uma pesquisa bibliográfica, representando uma tentativa sistemática do levantamento da prática da EA, no âmbito do ensino formal, sob o enfoque de revistas acadêmicas. A pesquisa bibliográfica foi desenvolvida com base na análise dos artigos, publicados entre 2007 e 2012, de três revistas que apresentam formato acadêmico e temática direcionada à EA.

A opção de um recorte temporal entre 2007 a 2012 decorreu em virtude de uma busca de equidade temporal das publicações das revistas, já que as revistas escolhidas para o estudo apresentam datas de criação diferenciadas.

A escolha por revistas, como fonte de dados, foi devido a essas não serem somente meios de divulgação e comunicação de trabalhos de pesquisa em EA, bem como de experiências dos educadores ambientais, retratadas por estes ou demais atuantes na área ambiental, mas são instrumentos que além de contribuírem para a legitimação, consolidação e fortalecimento desse campo de pesquisa, permitem a reflexão e o intercâmbio de experiências. Para a escolha das revistas foram considerados os seguintes critérios: temática direcionada a EA; formato acadêmico; publicação online; estar indexada e ser reconhecida pelo sistema Qualis; participar do acervo eletrônico do portal CAPES ou ser de acesso livre, e não estar vinculada a um Programa de Pós-Graduação.

As revistas e edições escolhidas para o estudo foram: Ambiente \& Educação

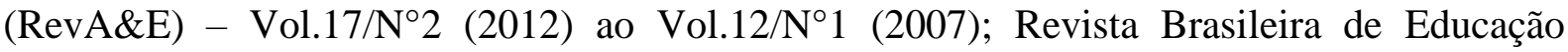

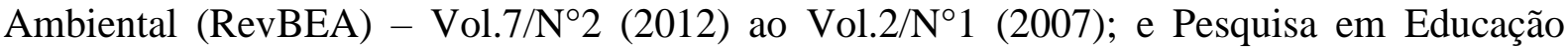

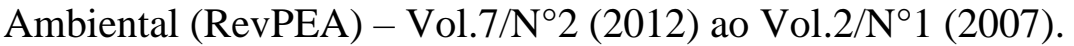

Outro importante periódico, a Revista Eletrônica do Mestrado em Educação Ambiental - REMEA, é muito tradicional, mas por estar vinculada a um Programa de PósGraduação optou-se por inclui-la num estudo futuro, complementar ao aqui apresentado.

A primeira etapa do trabalho foi identificar os artigos que apresentam práticas de EA junto ao ensino formal. Utilizou-se o Método de Análise de Conteúdo (BARDIN, 1977, p.95). Esse método é organizado em três momentos: a pré-análise, a exploração do material e o tratamento dos resultados, inferência e interpretação.

Primeiramente, fez-se o que Bardin chama de leitura flutuante, ou seja, estabeleceu-se contato com os artigos e assim foi conhecido o conteúdo textual, identificado suas impressões e orientações. Nessa etapa, foi desenvolvido um esboço de categorias advindas de 
similaridades de informações. Como o objetivo da pesquisa era conhecido, seguiu para identificação do universo de artigos susceptíveis ao fornecimento das informações para a continuidade do estudo, realizando-se, assim, uma análise categorial.

Para as denominações e definições das categorias, utilizou-se como referência a proposta de Carvalho e Farias (2011) que, no trabalho de balanço da produção científica em EA, classificaram os objetos de estudo segundo ênfase temática. As categorias dessas pesquisadoras serviram apenas como norteadoras do presente estudo, pois se optou em formular categorizações com abrangências distintas, devido às diferenças dos objetivos de trabalhos e das visões gerais das tendências temáticas.

Como forma de sistematizar as informações foram utilizadas questões norteadoras à categorização. Assim, realizaram-se as operações de classificação e agregação dos artigos em função das categorias pré-estabelecidas (Quadro 1).

Após a classificação, agregação dos artigos em categorias e identificação dos artigos objetos deste estudo, houve necessidade de uma nova análise categorial, já que os objetos de estudo, artigos enquadrados em Práticas de EA e o Ensino Formal, apresentam duas vertentes, os trabalhos que apresentam as experiências práticas de EA e os trabalhos que buscam junto ao público envolvido os significados individuais de Meio Ambiente, EA ou outras temáticas. Assim, baseada também em questões norteadoras, optou-se por uma nova classificação, sendo estas descritas no Quadro 1. 
Quadro 1- Categorias dos trabalhos de EA e Subcategorias da Práticas de EA e o Ensino Formal

\begin{tabular}{|c|c|}
\hline CATEGORIA & DESCRIÇÃO \\
\hline $\begin{array}{l}\text { CONCEPÇÕES } \\
\text { TEÓRICAS }\end{array}$ & $\begin{array}{l}\text { Buscam, exclusivamente por meio de fundamentos teóricos, a exposição, } \\
\text { conceituação, reflexão, compreensão e/ou discussão de temáticas focadas no meio } \\
\text { ambiente e/ou EA no ensino formal ou não formal. }\end{array}$ \\
\hline $\begin{array}{l}\text { PRÁTICAS DE EA E } \\
\text { O ENSINO NÂO } \\
\text { FORMAL }\end{array}$ & $\begin{array}{l}\text { Buscam apresentar experiências práticas de EA, voltadas para empresas, } \\
\text { comunidades, grupos sociais específicos (ribeirinhos, indígenas, quilombolas etc.), } \\
\text { em um contexto não escolar. Somam-se a estes trabalhos que buscam a compreensão } \\
\text { de significados (representações, percepções, concepções, etc.) de Meio Ambiente, } \\
\text { EA e outros temas voltados aos perfis e contexto citados. }\end{array}$ \\
\hline $\begin{array}{l}\text { PRÁTICAS DE EA } \\
\text { E O ENSINO } \\
\text { FORMAL }\end{array}$ & $\begin{array}{l}\text { Buscam apresentar experiências práticas de EA (ações estratégicas, programas, } \\
\text { projetos etc.), voltadas para o ensino formal nos seus diferentes níveis (infantil, } \\
\text { fundamental, médio, técnico, superior), incluindo as práticas voltadas à formação } \\
\text { docente. Somam-se a estes trabalhos que buscam a compreensão de significados } \\
\text { (representações, percepções, concepções etc.) de Meio Ambiente, EA e outros temas } \\
\text { voltados aos perfis e contexto citados. }\end{array}$ \\
\hline $\begin{array}{ll}\text { TENDÊNCIAS } & \text { DA } \\
\text { PRODUÇÃO } & \text { DE } \\
\text { ESTUDOS EM EA } & \end{array}$ & $\begin{array}{l}\text { Buscam recuperar, catalogar, sistematizar, investigar, avaliar e/ou analisar dados } \\
\text { quantitativos e/ou qualitativos da produção de pesquisa acadêmica (dissertações, } \\
\text { teses, artigos etc.), práticas educativas (projetos, atividades etc.) ou materiais } \\
\text { educativos (livros didáticos), desenvolvidas em âmbito formal ou não formal. }\end{array}$ \\
\hline $\begin{array}{ll}\text { EA } & \text { E } \\
\text { PESQUISADORES }\end{array}$ & $\begin{array}{l}\text { Buscam apresentar grupos de discussão e pesquisa, grupos técnicos e redes. A } \\
\text { apresentação, em geral, baseia-se na origem, composição, trajetória de pesquisa, } \\
\text { objetivos do grupo, ações etc. Encontram-se, também, nesta categoria, trabalhos que } \\
\text { apresentam informações de pesquisadores de maneira individual. }\end{array}$ \\
\hline OUTROS & $\begin{array}{l}\text { Trabalhos que não se enquadram em nenhuma das categorias mencionadas, podendo } \\
\text { ser trabalhos práticos que se distanciam da temática EA, trabalhos que tem como } \\
\text { objetivo apresentar informações sobre eventos nas áreas de Meio Ambiente e/ou } \\
\text { EA, e trabalhos que apresentam enfoques tanto no ensino formal quanto não formal, } \\
\text { sendo estes, em geral, apresentação de políticas públicas ou trabalhos pertencentes a } \\
\text { um grupo social. }\end{array}$ \\
\hline \multicolumn{2}{|c|}{ 'PRÁTICAS DE EA E O ENSINO FORMAL' } \\
\hline $\begin{array}{l}\text { IDENTIFICAÇÃO DE } \\
\text { SIGNIFICADOS }\end{array}$ & $\begin{array}{l}\text { Objetivam exclusivamente identificar, caracterizar e compreender os significados } \\
\text { (representações, percepções, concepções etc.) de Meio Ambiente, EA e outros } \\
\text { temas. Enquadra-se, também, nesta categoria, a avaliação de materiais didáticos, } \\
\text { cursos, entre outras, desde que não baseado apenas em análise documental e que } \\
\text { envolvam o contexto do ensino formal. }\end{array}$ \\
\hline $\begin{array}{l}\text { EXPERIÊNCIAS } \\
\text { PRÁTICAS }\end{array}$ & $\begin{array}{l}\text { Buscam apresentar as experiências práticas de EA (ações estratégicas, oficinas, } \\
\text { projetos, programas etc.), voltadas para o ensino formal nos seus diferentes níveis, } \\
\text { incluindo as práticas voltadas à formação docente. }\end{array}$ \\
\hline
\end{tabular}

\subsection{Os Dados}

Segundo Bardin (1977, p.100), "Desde a pré-análise devem ser determinadas operações: de recorte do texto em unidades comparáveis de categorização para análise temática e de modalidade de codificação para o registro dos dados". Assim, no presente estudo, identificaram-se as seguintes temáticas, índices de interesse e seus indicadores (Quadro 2). 
Quadro 2 - Descrição das Temáticas, Índices e Indicadores.

A. Temática: Instituição de Ensino (IE) - Índices: Nível de Ensino (Indicadores: Educação Infantil, Ensino Fundamental, Ensino Médio, Ensino Técnico, Ensino Superior, Formação Continuada, Outros, Ausência de Informação) e Categoria (Indicadores: Pública, Particular, Outros, Ausência de Informação). As informações analisadas nesta temática referem-se às IEs responsáveis pelos indivíduos que participaram das práticas, e não das instituições que as promoveram.

Continua...

...continuação.

B. Temática: Perfil do Público Envolvido - Índices: Desenvolvedor (Indicadores: Pesquisador, Professor, Ausência de Informação), Apoiador ${ }^{1}$ (Indicadores: Sim, Não), Participantes (Indicadores: Estudantes, Professores, Funcionários da IE, Pais, Membros da Comunidade) e Número de Participantes (Indicadores: 1 a 50 - baixíssima abrangência, 51 a 100 - baixa abrangência, 101 a 200 - média abrangência, 201 a 300 - elevada abrangência e Mais que 300 - elevadíssima abrangência).

C. Temática: Abrangência Temporal e Espacial - Índice: Duração da prática ${ }^{1}$ (Indicadores: Pontual evento único, Curto prazo - mais de um evento a uma prática que dura um semestre, Médio prazo prática se estende por mais de um semestre a um ano, Longo Prazo - prática que perdura por mais de um ano, Ausência de Informação), Espaço de Aprendizagem ${ }^{1}$ (Indicadores: Instituição de Ensino, Comunidade, Município, Outros, Ausência de Informação) e Região do país (Indicadores: Norte, Nordeste, Centro-Oeste, Sul, Sudeste, Outras, Ausência de Informação).

D. Temática: Temas e Áreas de conhecimentos ${ }^{1}$ - Índice: Temas ambientais (Indicadores: Fauna, Flora, Biodiversidade, Água, Resíduos, Sustentabilidade, Temas transversais e Outros) e Áreas de conhecimento (Indicadores: Sim, Não).

E. Temática: Proposta Metodológica ${ }^{1}$ - Índice: Método de ensino (Indicadores: Projetos, Ações estratégicas, Atividades, Intervenções, Oficinas e Programas), Estratégia (Indicadores: Ausente. Em virtude da ampla diversidade dos trabalhos não foi possível classificar as informações, realizando-se apenas a análise qualitativa desse índice), Técnica (Indicadores: As técnicas apresentaram-se em quantidade e complexidade que impediram uma delimitação categorial. Assim, optou-se por separá-las (palavras-chave), e através do Programa ManyEyes identificaram-se as técnicas mais comuns), Avaliação (Indicadores: Análise Comportamental, Entrevista, Material Produzido, Questionário, Relatos, Outros e Ausência de Informação).

F. Temática: Processo Educativo ${ }^{1}$ - Índice: Interdisciplinaridade (intercâmbio de conhecimentos das mais variadas disciplinas numa determinada prática); Transversalidade (não é limitada aos conhecimentos disciplinares; atinge os assuntos do dia a dia dos participantes; envolve questões/desafios que requeiram a análise crítica do aluno, o desejo por explicações/soluções, Conteúdo (transmissão de conteúdos/teoria), Análise crítica (desenvolvimento da arte do julgamento, da decisão), Ação (a atitude, a atuação). As identificações dos índices foram determinadas através da delimitação de seus significados e da análise do conteúdo textual, por meio de palavras-chave e questões norteadoras. Todos os indicadores foram afirmação e negação.

G. Temática: Significação ${ }^{2}$ - Índice: Significados (Indicadores: Meio Ambiente, EA, Diversos e Outros (mais de um significado), Técnica (Indicadores: Questionários, Análise Documental, Entrevista, Desenhos, Observações e Outros).

${ }^{1}$ Análise somente das práticas subcategorizadas como Experiências Práticas.

${ }^{2}$ Análise somente das práticas subcategorizadas como Identificação dos Significados.

Com os artigos a serem analisados e categorias, índices e indicadores delimitados passou-se à etapa de exploração do material. Por fim, seguiu-se a etapa de tratamento dos resultados obtidos e interpretação dos mesmos.

\section{Práticas em EA no âmbito do Ensino Formal}

\subsection{Produção das Revistas Acadêmicas em EA}

As revistas em estudo, no período compreendido entre 2007 a 2012, visando disseminar experiências, permitir debates e reflexões etc., publicaram 317 artigos sobre a temática EA, a partir de diferentes perspectivas. Foram diversos os temas e questões, desde relatos de experiências pontuais a artigos de cunho teórico-conceitual. Uma diversidade que 
se constitui numa das riquezas da área (FREITAS; GALIAZZI, 2010).

Os 317 artigos apresentaram as seguintes distribuições: 111 (35,0\%) na RevA\&E, 92 $(29,0 \%)$ na RevBEA e $114(36,0 \%)$ na RevPEA (Tabela 1). Em se tratando das relações artigos e categorias, destaca-se a categoria Concepções teóricas $(34,4 \%)$, seguida da Práticas de EA e o Ensino formal (25,6\%). Carvalho e Farias (2011), ao analisarem a produção científica em EA da ANPEd, identificaram como destaque os trabalhos relacionados à discussão de bases teóricas e metodológicas de propostas, práticas e concepções de EA, categoria por elas denominadas como Fundamentos da EA, seguidos das temáticas relacionadas ao ensino formal, como este estudo.

Tabela 1 - Distribuição de frequências do número de artigos por Categorias e por Revistas $(\mathrm{n}=317)$.

\begin{tabular}{|c|c|c|c|c|c|c|c|c|}
\hline \multirow[b]{2}{*}{ CATEGORIAS } & \multicolumn{2}{|c|}{ RevA\&E } & \multicolumn{2}{|c|}{ RevBEA } & \multicolumn{2}{|c|}{ RevPEA } & \multicolumn{2}{|c|}{ TOTAL } \\
\hline & FA & $\begin{array}{l}\text { FR } \\
(\%)\end{array}$ & FA & $\begin{array}{l}\text { FR } \\
(\%)\end{array}$ & FA & $\begin{array}{l}\text { FR } \\
(\%)\end{array}$ & FA & $\begin{array}{l}\text { FR } \\
(\%)\end{array}$ \\
\hline Concepções Teóricas & 38 & 34,2 & 27 & 29,3 & 44 & 38,6 & 109 & 34,4 \\
\hline Práticas de EA e o Ensino não formal & 12 & 10,8 & 17 & 18,5 & 9 & 7,9 & 38 & 12,0 \\
\hline Práticas de EA e o Ensino formal & 26 & 23,4 & 35 & 38,0 & 20 & 17,5 & 81 & 25,6 \\
\hline Tendências da produção de estudos em EA & 6 & 5,4 & 4 & 4,3 & 21 & 18,4 & 31 & 9,8 \\
\hline EA e os Pesquisadores & 20 & 18,0 & 4 & 4,3 & 17 & 14,9 & 41 & 12,9 \\
\hline Outros & 9 & 8,1 & 5 & 5,4 & 3 & 2,6 & 17 & 5,4 \\
\hline TOTAL & 111 & 35 & 92 & 29 & 114 & 36 & 317 & 100 \\
\hline
\end{tabular}

FA = Frequência absoluta; FR = Frequência relativa

Fonte: dados dos autores.

A mesma análise foi realizada por revista, com o intuito de identificar o perfil das publicações de cada uma delas (Tabela 1). A análise apontou que a RevA\&E apresentou a maioria de artigos categorizados como Concepções teóricas $(34,2 \%)$, já a RevBEA Práticas de EA e ensino formal (38,0\%), e a RevPEA Concepções teóricas $(38,6 \%)$.

Os dados apontaram uma concentração de artigos com foco nas discussões teóricas na RevA\&E e na RevPEA, provavelmente pelas mesmas apresentarem um formato unicamente acadêmico. Quanto à RevPEA, revista que surgiu a partir de um Encontro de Pesquisa em EA (EPEA) e que tem o papel de, também, divulgar as produções desse evento, apresentou neste estudo um perfil diferente do identificado por Carvalho e Farias (2011), que, ao analisarem a produção científica de 2001 a 2009 do EPEA, identificaram como predominantes os temas mais recorrentes àqueles expressados na categoria $E A$ no ensino formal, seguido da categoria Fundamentos da EA. Já a RevBEA é uma revista que apresenta um formato acadêmico e não acadêmico, possibilitando, assim, um acolhimento de textos produzidos no campo da EA, independentemente da sua natureza, o que pode justificar a maioria de artigos categorizados como Práticas de EA e o ensino formal.

De todos os artigos publicados no período mencionado, 81 artigos $(25,6 \%)$ abordaram a prática da EA junto ao ensino formal. Diante da polissemia da EA, da imensa área onde pode estar inserida, e da limitação de publicações de uma revista, considera-se que esse número de artigos $(25,6 \%)$ contribui para se pensar e se fazer EA no âmbito do ensino formal. Dentre os 81 artigos, 47 (58,0\%) enquadraram-se na categoria Experiências práticas e 34 $(42,0 \%)$ na categoria Identificação de Significados. Considerando que as Experiências Práticas apresentaram-se em uma quantidade superior aos trabalhos de Identificação de Significados, e que estes constituem "uma estratégia de pesquisa que se tornou popular entre os pesquisadores iniciantes da EA, preocupados em compreender melhor a área enquanto eles mesmos estão inserindo-se como pesquisadores e educadores ambientais" (CARVALHO; FARIAS; 2011; p. 127), poderia se pensar que, talvez, já haja uma melhor compreensão da área, o que não é um fato real, já que muitos trabalhos práticos apresentaram estudos prévios 
de Identificação de Significados, como uma forma de diagnóstico, antes do desenvolvimento das Experiências Práticas, como sugerem Pessoa e Braga, (2012, p. 105):

No primeiro momento, ocorreu a aplicação de um questionário exploratório (diagnóstico) que teve várias funções, entre elas a de servir de orientação para a construção dos roteiros de trabalho de campo e, principalmente, captar aspectos da percepção ambiental dos estudantes sobre as localidades que eles frequentavam no cotidiano [...].

\subsection{O perfil das práticas em EA}

\subsubsection{Instituição de ensino}

Em relação ao índice Categoria, $81,5 \%$ dos trabalhos foram realizados junto a IEs públicas. Em contrapartida, apenas 6,2\% foram realizados em IEs particulares. Muitos são os fatores que podem contribuir para esses números, entre eles está a maior facilidade das IEs públicas de desenvolvimento de trabalhos de pesquisa, além disso, há o envolvimento destas em parceria com Programas do Governo, como o Programa Mais Educação, que se vincula ao Projeto Político Pedagógico das IEs. Outros (4,9\%) refere-se a práticas realizadas em IEs públicas e particulares, categorizando uma ação de maior abrangência. Ações com esse caráter apresentam maiores dificuldades de execução e de pesquisa, o que pode explicar a baixa incidência dos mesmos (Tabela 2).

Tabela 2 - Distribuição de frequências das práticas de EA por Nível de Ensino e por Categorias das IEs.

\begin{tabular}{lll|lll}
\hline INSTITUIÇÃO DE ENSINO & & & & \\
NÍVEL DE ENSINO & FA & FR (\%) & CATEGORIA & FA & FR (\%) \\
\hline Educação Infantil & 2 & 2,5 & Pública & 66 & 81,5 \\
Ensino Fundamental & 25 & 30,9 & Particular & 5 & 6,2 \\
Ensino Médio & 10 & 12,3 & Outros & 4 & 4,9 \\
Ensino Técnico & 3 & 3,7 & Ausência de Informação & 6 & 7,4 \\
Ensino Superior & 15 & 18,5 & & & \\
Formação Continuada & 9 & 11,1 & & & \\
Ausência de Informação & 7 & 8,6 & & & \\
Outros & 10 & 12,3 & & & \\
\hline
\end{tabular}

Fonte: dados dos autores.

Além da Categoria, analisou-se o Nível de ensino. Entre os artigos destacam-se o ensino fundamental, apresentando um envolvimento em 30,9\% dos trabalhos, e o ensino infantil com presença em apenas 2,5\% (Tabela 2). Kawasaki et al. (2009) em um estudo sobre a EA nos EPEAs (2001-2007) identificaram uma predominância de trabalhos de EA que focalizam a educação básica, e, dentre estes, a EA nos ensinos fundamental e médio. Identificaram, também, a baixa abordagem de trabalhos de EA junto ao ensino infantil, como no estudo em questão.

A maioria das práticas vinculadas ao ensino fundamental provavelmente decorrem dos PCNs para o Ensino Fundamental, que estabelecem orientações diretas sobre os temas, facilitando/cobrando o desenvolvimento destes junto aos alunos. Já os dados da educação infantil demonstram que há um baixo interesse nesse nível de ensino, expondo uma contradição entre o discurso geral da EA, que enfatiza a necessidade de desenvolver práticas educacionais voltadas para todos os públicos e níveis escolares (KAWASAKI et al., 2009). Há, também, um contraponto; segundo Montanhim, Caron e Cinquetti (2011) é muito comum ouvir a crença de que as ações de EA deveriam se voltar para as crianças, consideradas a grande esperança para a mudança de atitudes, entretanto, os educadores que se dedicam à 
educação infantil sabem que não é tão simples conduzir ações educativas com crianças pequenas, seja sobre a temática ambiental, seja sobre outras, por distintas razões. Esses apontamentos evidenciam a necessidade de mais estudos juntos a esse nível de ensino a fim de permitir reflexões, desenvolvimento de metodologias de ensino etc., contribuindo para sanar essa deficiência.

\subsubsection{Perfil do público envolvido}

O processo que envolve e permeia a EA tem que ser contínuo e baseado na (re) construção da educação nos valores humanos, envolvendo a escola, família e comunidade local (SOUZA; PEREIRA, 2011). Caso seja feita uma análise por indicador, esse envolvimento mencionado pelos autores, importante para a prática em EA, não pode ser observado no estudo em questão, onde a maioria dos trabalhos $(38,3 \%)$ apontou a participação de apenas estudantes. Considera-se que a diversidade de públicos na prática educativa favorece a troca de conhecimentos e experiências. Neste estudo, esse cenário seria o envolvimento entre estudantes, professores, funcionários, pais e membros da comunidade, o qual apresentou um baixo resultado, correspondendo a apenas 2,5\% dos artigos (Tabela 3). Estes resultados podem não ser tão pessimistas quanto parecem, pois se somados os indicadores que apresentam mais de uma tipologia de indivíduos o resultado $(41,9 \%)$ supera as práticas que apresentam o envolvimento de apenas estudantes/professores. Mas este ainda não supera a totalidade de trabalhos realizados unicamente com um tipo de público.

Tabela 3 - Distribuição de frequências das práticas de EA por Participantes, Abrangência de Participantes, Desenvolvedor e Apoiador.

\begin{tabular}{|lll|lll}
\hline PERFIL DO PÚBLICO ENVOLVIDO & & & \\
\hline PARTICIPANTES & FA & FR $(\%)$ & DESENVOLVEDOR & FR (\%) \\
\hline Estudantes & 31 & 38,3 & Professor & 7 & 8,6 \\
Professores & 16 & 19,8 & Pesquisador & 55 & 67,9 \\
E C & 2 & 2,5 & Professor e Pesquisador & 2 & 2,5 \\
E P & 1 & 1,2 & Ausência de Informação & 17 & 21,0 \\
\hline E Pr & 11 & 13,6 & APOIADOR & FA & FR (\%) \\
\hline E Pr C & 3 & 3,7 & Sim & 25 & 53,2 \\
E Pr F & 5 & 6,2 & Não & 22 & 46,8 \\
\hline E Pr F C & 3 & 3,7 & QUANTIDADE DE PARTICIPANTES & FA & FR (\%) \\
\hline E Pr F P C & 2 & 2,5 & 1 a 50 & 30 & 37,0 \\
E Pr P & 2 & 2,5 & 51 a 100 & 10 & 12,3 \\
E Pr P C & 2 & 2,5 & 101 a 200 & 6 & 7,4 \\
\hline E Pr F P & 3 & 3,7 & 201 a 300 & 4 & 4,9 \\
& & & Mais que 300 & 6 & 7,4 \\
& & & Ausência de Informação & 25 & 30,9 \\
\hline
\end{tabular}

Onde: E=Estudantes, $\mathrm{Pr}=$ Professores, $\mathrm{F}=$ Funcionários, $\mathrm{P}=$ Pais, $\mathrm{C}=$ Comunidade.

Fonte: dados dos autores.

A maioria dos trabalhos apresentou uma baixíssima abrangência $(37,0 \%)$, resultado que aponta para a preferência de desenvolvimento de trabalhos de pesquisa a um pequeno público. Trabalhar com poucos indivíduos pode até facilitar o desenvolvimento das práticas, mas é sabido que a possibilidade de maiores resultados se dá em uma amostra maior (Tabela $3)$.

Optou-se, também, pela análise do perfil dos desenvolvedores dos trabalhos, e foi observado um destaque para práticas desenvolvidas por pesquisadores $(67,9 \%)$ (Tabela 3). Resultado esperado por saber que o trabalho foi pautado em revistas acadêmicas. Reis et al. (2012), em um estudo sobre a EA na escola básica, identificaram a desinformação dos 
professores desse nível de ensino sobre as formas de divulgação dos conhecimentos produzidos sobre EA nos meios científicos, desconhecimento que dificulta a apropriação consistente de saberes necessários ao trabalho educativo. Diante disso, há necessidade de estimular professores a desenvolverem e publicarem seus trabalhos e, assim, aproximá-los da produção científica.

A participação de apoiadores, tais como: órgãos governamentais, empresas, outras instituições de ensino etc., nas práticas educativas, em geral, ocorre como uma espécie de apoio à comunidade escolar, contribuindo com novos conhecimentos, em geral técnicos, favorecendo o processo ensino-aprendizagem. No estudo em questão, essa participação esteve presente em 53,2\% dos trabalhos (Tabela 3). Este resultado provavelmente decorre da maioria dos trabalhos serem desenvolvidos por pesquisadores, que, para muitos, já se capacitaram tecnicamente para o estudo que irão desenvolver, afastando-os da necessidade de apoiadores.

\subsubsection{Abrangência temporal e espacial}

Ao considerar a distribuição espacial dos trabalhos, segundo Regiões do país, tem-se que a maior concentração destes se encontra na região Sudeste (33,3\%), seguida da região Sul $(23,5 \%)$ (Tabela 4). Carvalho (2008), em um estudo de mapeamento da EA por meio de uma pesquisa em rede, identificou que RS e SP destacaram-se com as maiores concentrações de educadores/especialistas/pesquisadores, sendo que, o Rio Grande do Sul foi caracterizado como o líder em instituições que atuam na área.

Tabela 4 - Distribuição das práticas de EA por Região do país, Espaço de Aprendizagem e Duração

\begin{tabular}{|lll|llll}
\hline ABRANGÊNCIA TEMPORAL E ESPACIAL & & & \\
\hline ESPAÇO APRENDIZAGEM & FA & FR $(\boldsymbol{\%})$ & DURAÇÃO & FA & FR (\%) \\
\hline E & 13 & 27,7 & Pontual & 3 & 6,4 \\
E C & 6 & 12,8 & Curto prazo & 11 & 23,4 \\
E C M & 1 & 2,1 & Médio prazo & 9 & 19,1 \\
E C M O & 1 & 2,1 & Longo prazo & 13 & 27,7 \\
E C O & 8 & 17,0 & Ausência de Informação & 11 & 23,4 \\
\hline E M O & 3 & 6,4 & REGIÃO DO PAÍS & FA & FR (\%) \\
\hline E O & 9 & 19,1 & Norte & 7 & 8,6 \\
O & 6 & 12,8 & Nordeste & 16 & 19,8 \\
& & & Centro-oeste & 8 & 9,9 \\
& & & Sudeste & 27 & 33,3 \\
& & & Sul & 19 & 23,5 \\
& & & Outras & 3 & 3,7 \\
\hline
\end{tabular}

Onde: $\mathrm{E}=$ Escola, $\mathrm{C}=$ Comunidade, $\mathrm{M}=$ Município, $\mathrm{O}=$ Outros.

Fonte: dados dos autores.

Trabalhou-se com duas Revistas que tem suas bases nas mesmas Regiões onde houve predominância das práticas, ou seja, Sudeste - base da RevPEA, e Sul - base da RevA\&E. Sabe-se da não existência de barreiras territoriais para publicações de artigos em revistas acadêmicas, assim, esse fator deve relacionar-se à falta de divulgação das mesmas em outras regiões, o que aponta para a necessidade de melhorar esse aspecto, contribuindo para a diversidade dos trabalhos do ponto de vista territorial, "além da importância de políticas de estímulo ao equilíbrio regional, bem como de desenvolvimento da pesquisa em EA nas demais regiões do país" (CARVALHO; FARIAS, 2011, p. 130).

Diante da análise da duração das práticas, observou-se pouca variação entre os indicadores curto, médio e longo prazo, mas considerando a duração mais presente nos 
artigos, destacam-se as práticas com longa duração $(27,7 \%)$, as quais favorecem a exploração do conhecimento de maneira mais profunda. Outra informação a ser enfatizada refere-se à baixa quantidade de trabalhos pontuais $(6,4 \%)$, sendo este um dado positivo quando se fala em práticas educativas, já que as mesmas não são interessantes, pois os impactos destas, em geral, são pouco expressivos (Tabela 4).

Para que as informações sensibilizem os alunos e provoquem o início de um processo de mudança de comportamento, é preciso que os mesmos estabeleçam ligações entre o que aprendem e a sua realidade cotidiana, além do que já conhecem (BRASIL, 1997) e, para isso, uma das alternativas é a interação dentro da escola, e desta com outros setores, tais como a comunidade e município. Se for realizada uma análise por indicador tem-se como resultado uma maioria de trabalhos $(27,7 \%)$ desenvolvidos no próprio ambiente escolar, não inovando em relação aos espaços utilizados para o desenvolvimento das práticas de EA (Tabela 4). Como identificado por Kawasaki et al. (2009), que, na análise de trabalhos apresentados nos EPEAs, não identificaram outros espaços não formais de ensino, além de Unidades de Conservação, nos trabalhos sobre contextos escolares. Ainda, segundo a análise por indicador, o indicador ideal, que seria o envolvimento de trabalhos na escola, comunidade, município e outros, apresentou-se em apenas 2,1\% das práticas, onde outros abrangeram os mais diversos espaços, desde outros municípios, como uma área de camping, cursos d'água específicos etc.

Poderia ser um resultado pessimista, mas se somadas todas as práticas que envolvem mais de um ambiente poderá ser observado que a maioria das práticas incluem outros ambientes além do espaço escolar, e que esses espaços são valorizados pelos professores/pesquisadores, tornando-os motivadores ao tratamento da temática ambiental.

\subsubsection{Temas e áreas de conhecimento}

Considerando que são muitos os temas que podem e são trabalhados nas mais diversas práticas em EA, e que as mesmas, muitas vezes, também são abrangentes e trabalham com diversos temas simultaneamente, optou-se por analisar, quando possível, o principal tema e, com o intuito de facilitar a análise dos dados, o mesmo foi separado em áreas. Considerando a separação de áreas, Outros foi o mais presente nos trabalhos analisados, perfazendo 44,7\% destes (Tabela 5). Os temas inclusos na área Outros são: permacultura, geotecnologia, agenda 21, diversos (ausência de um tema principal) etc. Em seguida, presente em 17,0\% dos trabalhos, encontra-se o tema Resíduos (gestão, lixão, aterro, lixo). No trabalho de analisar dados de diversas experiências de EA por escolas públicas e particulares, Segura (2001) identificou que as questões e estratégias em evidência eram lixo, horta, reciclagem, passeio e plantio de árvores. Neta e Fonseca (2012), ao analisarem projetos de escolas públicas e particulares do Distrito Federal, identificaram que os projetos, em sua maioria, basearam-se em atividades como coleta seletiva, cultivo de hortas e reciclagem. Esses dados apontam para uma tendência de trabalhos com a temática resíduos.

No que tange à presença das disciplinas nas práticas de EA, tem-se como informações que as mesmas não foram citadas na maioria dos artigos (63,8\%) (Tabela 5). Como já observado, a maioria dos trabalhos foram desenvolvidos por pesquisadores, o que pode ocasionar a ausência de informações a respeito das disciplinas, já que muitos trabalhos desenvolvidos por pesquisadores ocorrem em turnos diferentes do turno escolar, ou foram desenvolvidos nos horários de aula apenas ocupando o horário de uma disciplina, mas não correspondendo em uma associação com a mesma. Quando presentes, algumas das disciplinas citadas foram: Ciências, Biologia, Física, Geotecnologia etc. Segundo censo realizado pelo Inep/MEC, para analisar a EA nas escolas de educação básica do país, a maior parte das escolas realizam os projetos a partir de uma única disciplina, em segundo lugar, a partir da integração de duas ou mais disciplinas. No que diz respeito às disciplinas específicas, 
observou-se uma maior relevância das disciplinas Ciências Naturais (TRAJBER; MENDONÇA, 2007).

Tabela 5 Distribuição das práticas de EA, os Temas Ambientais e as Áreas de Conhecimento TEMAS E ÁRES DE CONHECIMENTO

\begin{tabular}{lll|lll}
\hline TEMAS & FA & FR $(\%)$ & ÁREAS DE CONHECIMENTO & FA & FR $(\%)$ \\
\hline Fauna & 2 & 4,3 & Ausência de Informação & 30 & 63,8 \\
Flora & 2 & 4,3 & Todas as disciplinas & 1 & 2,1 \\
Biodiversidade & 4 & 8,5 & 1 disciplina & 8 & 17,0 \\
Água & 2 & 4,3 & 2 ou mais disciplinas & 8 & 17,0 \\
Resíduos & 8 & 17,0 & & & \\
Sustentabilidade & 5 & 10,6 & & & \\
Temas Transversais & 3 & 6,4 & & & \\
\hline Outros & 21 & 44,7 & & & \\
\hline
\end{tabular}

Fonte: dados dos autores.

\subsubsection{Propostas metodológicas}

Quanto ao índice Métodos de ensino houve um destaque para os Projetos (55,3\%), em contraposição as Oficinas (4,3\%) (Tabela 6). Carvalho (2008), ao apresentar o mapeamento da EA em uma pesquisa em rede, utilizou-se de categorias para identificar as atividades de EA, mesmo citando modalidades diferentes das estabelecidas neste estudo, identificou a predominância da modalidade 'projeto' nas atividades de EA e apontou que essa condição também já apareceu em levantamentos anteriores, realizados por órgãos governamentais.

Tabela 6 Distribuição das práticas de EA por Método de Ensino, Estratégias e Avaliações.

\begin{tabular}{lll|lll}
\multicolumn{2}{l}{ PROPOSTAS METODOLÓGICAS } & & & & \\
MÉTODO DE ENSINO & FA & FR $(\%)$ & AVALIAÇÃO & FA & FR (\%) \\
\hline Ações estratégicas & 6 & 12,8 & Análise comportamental & 5 & 10,6 \\
Atividade & 6 & 12,8 & Entrevista & 1 & 2,1 \\
Intervenções & 3 & 6,4 & Material produzido & 5 & 10,6 \\
Oficina & 2 & 4,3 & Questionário & 7 & 14,9 \\
Programa & 4 & 8,5 & Relatos & 3 & 6,4 \\
Projeto & 26 & 55,3 & Outros & 17 & 36,2 \\
& & & Ausência de informação & 9 & 19,1 \\
\hline
\end{tabular}

\begin{tabular}{|c|c|}
\hline \multicolumn{2}{|l|}{ ESTRATÉGIA } \\
\hline Ecopedagogia - Educação Permacultural & Viveiro florestal \\
\hline Explorar o meio e produzir um vídeo aula & Abordagem teórica com percepção sensória \\
\hline Utilização de aplicativos na área de geotecnologia & Teatro do Oprimido \\
\hline Horta escolar & Educação patrimonial (museu) \\
\hline $\begin{array}{l}\text { Utilizar as metas propostas pela ONU através do } 7^{\circ} \\
\text { Objetivo do Milênio, Qualidade de Vida e Respeito ao } \\
\text { Meio Ambiente }\end{array}$ & $\begin{array}{l}\text { Inserção da dimensão ambiental via } \text { CTS } \\
\text { (Ciência/Tecnologia/Sociedade) no processo de ensino } \\
\text { e aprendizagem de Biologia }\end{array}$ \\
\hline $\begin{array}{l}\text { Teoria da Aprendizagem Significativa - Alternativas } \\
\text { de Implantação de Sistemas de Captação e } \\
\text { Aproveitamento de Água de Chuva }\end{array}$ & $\begin{array}{l}\text { Biomonitoramento participativo da qualidade da água } \\
\text { (EA para sensibilização, conscientização e } \\
\text { mobilização) }\end{array}$ \\
\hline
\end{tabular}

Fonte: dados dos autores.

Em relação aos indicadores, de maneira geral, observou-se que em muitos casos não há uma classificação baseada em conceitos teóricos, classificando as práticas didaticamente. Segura (2001), ao analisar dados de diversas experiências de EA, identificou como primeira característica certa desinformação quanto ao significado de projeto, que, no seu entender, precisa articular ações segundo objetivos claros. Os trabalhos caracterizavam-se mais como 
atividades pontuais ou desarticuladas do que como projetos.

Em virtude, especialmente, da diversidade dos trabalhos, não se realizou uma análise categorial das Estratégias propostas pelos estudos, consequentemente, esta não foi analisada com métodos quantitativos. Assim, optou-se por separá-las e, para este artigo foram apenas descritas algumas (Tabela 6) para que sirvam como referência. Interessante ressaltar que não houve estratégias similares nos trabalhos analisados, evidenciando uma diversidade dos trabalhos e identificando-se com o que mencionam Santos e Martins (2007), "o campo da EA apresenta uma diversidade de abordagens práticas, apresentadas principalmente nos relatos de experiência, que vão desde atividades de sensibilização até atividades reflexivas problematizadoras da realidade socioambiental na qual estamos imersos".

Como as estratégias, o índice Técnicas não foi analisado quantitativamente. Este apresentou um perfil complexo para categorização, então, optou-se por separar palavraschaves relacionadas às técnicas citadas pelos autores ao longo dos textos e fazer uso do Programa Many Eyes a fim de obter uma demonstração ilustrativa das principais técnicas utilizadas nos trabalhos (Figura 1). Conforme a ilustração, as técnicas mais citadas foram: oficinas, aulas de campo, palestras, atividades, dinâmicas, discussões, entrevistas, aulas expositivas e visitas etc. Comparando os dados referentes às técnicas com o enfoque do processo educativo tem-se que ambos apresentam um direcionamento para atividades relacionadas à prática/ação.

Figura 1- Técnicas das práticas de EA

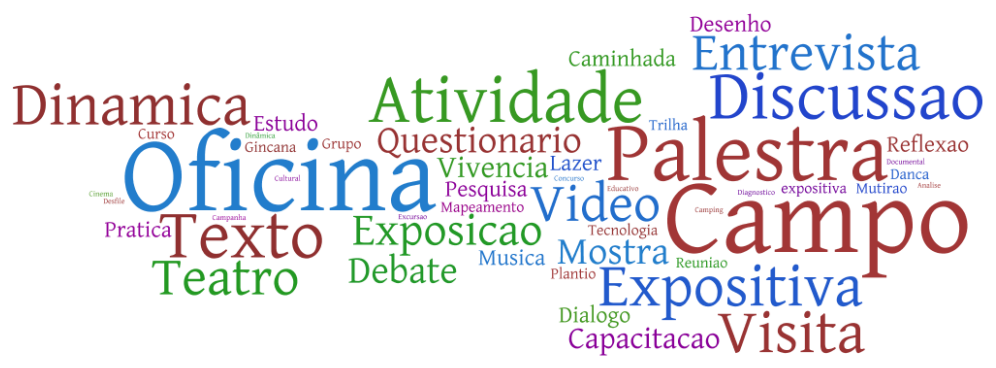

Fonte: dados dos autores.

Os resultados referentes à Avaliação evidenciaram um destaque para o indicador Outros $(36,2 \%)$, ou seja, uma combinação de diversos meios, como por exemplo, análise comportamental, entrevista e questionário, ou material produzido e entrevista, entre outros. A junção de técnicas permite mais elementos quantitativos e qualitativos, garantindo uma análise mais completa, e, assim, uma maior riqueza dos resultados (Tabela 6). Destaca-se, a seguir, um trecho de um dos artigos analisados que evidenciam o processo de avaliação baseado nos indicadores pertencentes a esse índice:

A avaliação ocorreu de forma qualitativa e seguiu duas dimensões: uma mais
clássica, onde se coletou informaçães a respeito do conteúdo; e outra mais
relacionada à compreensão de valores socioambientais, sendo avaliada a visão
crítica do aluno. A participação dos alunos durante as intervenções, a discussão e a
postura após a intervenção foram avaliadas no transcorrer do trabalho, através da
Observação Direta. (ALMEIDA; COSTA-SANTANA; TONSO, 2010, p.215, grifo
nosso) - Processo de Avaliação Outro'.

Segundo Gutierrez-Perez (2005), na EA há um baixo consenso quanto às metodologias, sobre os referenciais teóricos mais convenientes, as formas de intervenção mais apropriadas e os modelos de trabalho mais recomendáveis para resolver os problemas socioambientais. Desse modo, é possível identificar os motivos da dificuldade de análises quantitativas e qualitativas dos indicadores dessa temática. 


\subsubsection{Processo educativo}

A maioria dos trabalhos $(51,1 \%)$ apresentou a interdisciplinaridade como estratégia nas suas práticas (Tabela 7). Apesar do resultado, a ausência da interdisciplinaridade em 48,9\% das práticas expõe um não cumprimento da legislação, já que, segundo a Política Nacional de EA (PNEA), as ações de estudos, pesquisas e experimentações vinculadas a PNEA deverão se voltar para o desenvolvimento de instrumentos e metodologias, visando à incorporação da dimensão ambiental, de forma interdisciplinar, nos diferentes níveis e modalidades de ensino (BRASIL, 1999).

A maioria dos artigos $(76,6 \%)$ analisados apresentou a presença da transversalidade nas práticas (Tabela 7). Como no estudo da interdisciplinaridade, a ausência da transversalidade em $23,4 \%$ das práticas expôs, novamente, um não cumprimento da legislação. A Resolução CNE/CP 2/2012 estabelece que a EA nas IEs deve "contemplar a abordagem curricular integrada e transversal, contínua e permanente em todas as áreas de conhecimento, componentes curriculares e atividades escolares e acadêmicas" (CNE, 2012).

Quanto ao enfoque do processo educativo, a maioria das práticas baseou-se em um perfil conteúdo - análise crítica - ação, estando presentes em 51,1\% dos trabalhos (Tabela 7). Se analisarmos as definições e os objetivos da EA, conforme proposto na Carta de Belgrado e em Tbilisi, respectivamente, torna-se claro que a expectativa da EA é bem mais ampla do que meramente informar ou transmitir conhecimentos. Não basta saber, é necessário tocar o indivíduo profundamente, desenvolver seu lado sensível e estimular sua criatividade. Dar, a cada um, capacidade de solucionar problemas e de engajar-se em processos de mudanças (PÁDUA, 2001), assim, torna-se claro que, sob o ponto de vista do enfoque utilizado, as práticas que têm sido publicadas estão alinhadas com os objetivos da EA. Quando se analisam os enfoques de maneira individual, as práticas com enfoque no conteúdo foram as menos citadas (34\%), já as práticas com enfoque na ação foram destaque, presentes em $96 \%$ dos trabalhos.

Tabela 7- Distribuição da interdisciplinaridade, transversalidade e enfoque educativo nas práticas de EA

\begin{tabular}{|c|c|c|c|c|c|}
\hline \multicolumn{6}{|l|}{ PROCESSO EDUCATIVO } \\
\hline INTERDISCIPLINARIDADE & FA & FR $(\%)$ & TRANSVERSALIDADE & FA & FR $(\%)$ \\
\hline Sim & 24 & 51,1 & Sim & 36 & 76,6 \\
\hline Não & 23 & 48,9 & Não & 11 & 23,4 \\
\hline ENFOQUE & FA & FR $(\%)$ & Conteúdo (teoria) & FA & FR $(\%)$ \\
\hline \multirow{8}{*}{$\begin{array}{l}\text { T C A } \\
\text { T C } \\
\text { T A } \\
\text { C A } \\
\text { A }\end{array}$} & \multirow{8}{*}{$\begin{array}{l}24 \\
2 \\
5 \\
12 \\
4\end{array}$} & \multirow{8}{*}{$\begin{array}{l}51,1 \\
4,3 \\
10,6 \\
25,5 \\
8,5\end{array}$} & Sim & 16 & 34,0 \\
\hline & & & Não & 31 & 66,0 \\
\hline & & & Análise Crítica & & \\
\hline & & & Sim & 38 & 80,9 \\
\hline & & & Não & 9 & 19,1 \\
\hline & & & Ação & & \\
\hline & & & Sim & 45 & 95,7 \\
\hline & & & Não & 2 & 4,3 \\
\hline
\end{tabular}

Onde: $\mathrm{T}=$ Teoria (Conteúdo), $\mathrm{C}=$ Análise Crítica, $\mathrm{A}=$ Ação.

Fonte: dados dos autores.

Destacam-se, a seguir, trechos de artigos analisados que evidenciam a presença da interdisciplinaridade, da transversalidade e do enfoque do processo educativo das práticas:

Dentre as oficinas, uma delas foi a 'Horta em Mandala' [...]. Este trabalho é muito difundido pela Permacultura, pois envolve princípios como sucessão natural, melhor 
uso dos espaços, diversificação de plantas, integração animal, dentre outras. Esta proposta nas EFA's foi elaborada conjuntamente com parte do corpo docente, e interligada com as disciplinas curriculares, como matemática, geografia, construções rurais, artes e agroecologia. (SANTOS; BARBOSA; CAON, 2012, p. 127, grifo nosso) - Interdisciplinaridade.

Durante o processo formativo procurou-se valorizar esses aspectos, principalmente quando da realização dos trabalhos de campo e estudos do meio, enquanto abordagem possibilitadora de uma reinterpretação das condições de vida da comunidade e problematização da realidade local por meio da observação e representação focadas nos temas estruturantes (PANZERI; COMPIANI; ALBERTO JR, 2010, p. 123, grifo nosso) - Transversalidade.

O encontro também contou com um momento de cunho mais teórico, quando foram discutidos pressupostos histórico-filosóficos do campo da EA e o "Antropocentrismo" nas questões ambientais [...]. As leituras em grupo, seguidas da confecção de cartazes, trouxeram profundas reflexões e total envolvimento do grupo com as questões abordadas. (DOLCI; SHIRAZAWA; KINDEL, 2008, p. 138, grifo nosso) - Conteúdo, Análise Crítica e Ação.

\subsubsection{Significação}

Em relação aos Significados observou-se que a maioria das práticas relacionadas a essa temática são baseadas na busca pelos significados de Meio Ambiente (38,2\%), acrescidas suas vertentes, como crise ambiental, conscientização ambiental etc. (Tabela 8). Segundo Marin, Oliveira e Comar (2003), a percepção tem sido estudada, na maioria das vezes, por meio da identificação de conceitos de meio ambiente e dos referentes a fenômenos e problemas ambientais, conforme identificado neste estudo.

Tabela 8 - Distribuição das práticas de EA por Significados e por Técnicas de Identificação destes.

\begin{tabular}{lll|lll}
\hline SIGNIFICAÇÃO & \multicolumn{1}{l}{} & & & \\
\hline SIGNIFICADOS & FA & FR $(\%)$ & TÉCNICAS & FA & FR (\%) \\
\hline Meio Ambiente & 13 & 38,2 & Desenhos & 3 & 8,8 \\
Educação Ambiental & 9 & 26,5 & Entrevistas & 3 & 8,8 \\
MA e EA & 6 & 17,6 & Mapa Mental & 1 & 2,9 \\
Outros & 6 & 17,6 & Outros & 15 & 44,1 \\
& & & Questionários & 12 & 35,3 \\
\hline
\end{tabular}

Fonte: dados dos autores.

Em relação às técnicas utilizadas para os estudos de significados, foi possível observar uma predominância do indicador Outros $(44,1 \%)$, sendo este composto por mais de uma das técnicas citadas, tais como uma combinação de mapa mental e questionários, entrevistas e desenhos, entre outras (Tabela 8). Como no processo de avaliação, a junção de técnicas permite mais elementos quantitativos e qualitativos, garantindo uma análise mais completa, e, assim, uma maior riqueza dos resultados. Quando se analisa o uso de uma única técnica, como nos Métodos de avaliação, observa-se uma predominância do uso de questionário. $\mathrm{O}$ uso dessa técnica é comum, provavelmente, em virtude de constituir-se como uma técnica rápida e barata para obtenção de informações, além de não exigir treinamento de pessoal.

Um destaque ao indicador Ausência de Informação, presente em grande parte dos índices. Entende-se que as informações analisadas neste estudo são relevantes, em especial quando se estuda a possibilidade de reaplicabilidade dos trabalhos, portanto, com este estudo 
aproveita-se a oportunidade de alertar os pesquisadores no sentido de atentarem à menção de dados quando apresentarem trabalhos em instrumentos que servem como fonte $\mathrm{e}$ compartilhamento de informações.

\section{Considerações Finais}

A EA tem sido construída com diversos conceitos e abordagens, diferindo apenas no caminho e na forma de se construir o processo educacional. Como qualquer outra área do conhecimento, apresenta lacunas e falhas e possui orientações generalistas duvidosas. Por outro lado, representa a esperança de mudanças e a vontade de inserir a dimensão ambiental como pauta de uma nova revisão conceitual das ciências (SATO; GAUTHIER; PARIGIPE, 2005). Este estudo buscou a identificação da prática de EA que tem sido publicada em três revistas acadêmicas, no período compreendido entre 2007 a 2012. Em virtude desse recorte, decorrem limitações, as quais não permitem criar generalizações para os artigos de outras revistas e outras datas.

As práticas em EA, no âmbito do ensino formal, apresentam um perfil predominante aplicado a instituições públicas e de ensino fundamental, concentradas na região Sudeste do país. São práticas de longo prazo, desenvolvidas por pesquisadores, nas quais há participação de apoiadores. Envolvem, prioritariamente, estudantes em uma baixíssima abrangência e são desenvolvidas no espaço escolar. Envolvem diversos temas ambientais e quantidade e tipologia de disciplinas não definidas. Há predominância tanto da interdisciplinaridade quanto da transversalidade e um enfoque educativo em conteúdo - análise crítica - ação. A proposta metodológica baseia-se no método de ensino de projetos, estratégias e técnicas diversas e processo de avaliação caracterizado com uma mistura de técnicas. Quanto aos significados, houve predominância da busca por significados de meio ambiente fazendo uso de técnicas diversas.

O resultado corrobora a diversidade existente na área, especialmente em alguns indicadores, como por exemplo, a diversidade de espaços de aprendizagem, técnicas de avaliação etc., porém assinala algumas lacunas que precisam ser preenchidas, como a tentativa de estimular conceitos adequados quanto às propostas metodológicas, cumprimento da legislação quanto a interdisciplinaridade e a transversalidade etc. Através desse perfil é possível identificar caminhos ainda não percorridos e, com isso, incentivar o desenvolvimento de novos estudos direcionados a esses, além de fazer uso dos aspectos já consolidados, aproveitando e reconhecendo o valor das pesquisas.

Conhecer esse perfil das práticas em EA se configura não só como um dos pressupostos básicos para avaliar como vem se desenvolvendo a EA no contexto acadêmicocientífico, mas, também, como um parâmetro norteador para os estudiosos que utilizam esse meio para divulgar seus estudos, para os que as utilizam como referenciais para seus trabalhos e para os que avaliam a submissão de artigos.

\section{Referências}

ALMEIDA, E. M. P.; COSTA-SANTANA, P. M.; TONSO, S. O papel da literatura infantil como instrumento na reflexão e busca de soluções dos problemas ambientais. Ambiente \& Educação, Rio Grande, RS, Brasil, v. 15, n. 1, p. 207-228, 2010.

\section{BARDIN, L. Análise de Conteúdo. Lisboa: Edições 70, 1977.}

BRASIL. Secretaria de Educação Fundamental. Parâmetros curriculares nacionais. V. 9 Meio Ambiente e Saúde. Brasília: MEC/SEF, 1997. 
BRASIL. Lei $n^{\circ}$ 9.795, de 27 de abril de 1999. Dispõe sobre a educação ambiental, institui a Política Nacional de Educação Ambiental e dá outras providências. Brasília: Casa Civil, 1999. Disponível em: <http://www.planalto.gov.br/ccivil_03/leis/19795.htm>. Acesso em: 20 nov. 2015.

CARVALHO, I. C. M. Mapeando a educação ambiental desde uma pesquisa em rede. Revista Brasileira de Educação Ambiental, Brasília, v. 3, n. 1, p. 35-49, Jun. 2008.

CARVALHO, I. C. M.; FARIAS, C. R. O. Um balanço da produção científica em educação ambiental de 2001 a 2009 (ANPEd, ANPPAS e EPEA). Revista Brasileira de Educação, Rio Grande, RS, Brasil, v. 16, n. 46, p. 119-134, Jan./Abr. 2011,

CONSELHO NACIONAL DE EDUCAÇÃO (CNE). Resolução $n^{\circ}$ 2, de 15 e junho de 2012. Estabelece as Diretrizes Curriculares Nacionais para a Educação Ambiental. Ministério da Educação, Brasília: Diário Oficial da União, Brasília, 18 de junho de 2012, Seção 1, p. 70.

DOLCI, D. S.; SHIRAZAWA, J.; KINDEL, E.A.I., Educação ambiental: vivenciando teoria e prática através de um curso de formação continuada. Ambiente \& Educação, Rio Grande, RS, Brasil, v. 13, n. 1, p. 133-150, 2008.

FREITAS, J. V.; GALIAZZI, M. C. Apresentação. Revista Brasileira de Educação Ambiental, Rio Grande, v.5, n. 1, p. 2, Dez. 2010.

GUTIERREZ-PEREZ J. Por uma formação dos profissionais ambientalistas baseada em competências de ação. In: SATO, M., CARVALHO, I. (Orgs.). Educação ambiental: pesquisa e desafios. Porto Alegre: Artmed, 2005, p.119-133.

KAWASAKI, C. S.; CARVALHO, L. M.; ROSA, A. V.; BONOTTO, D. M. B.; OLIVEIRA, H. T.; CINQUETTI, H. S. C; SANTANA, L. C.; CAVALARI, R. M. F. A pesquisa em educação ambiental nos EPEAs (2001-2007): natureza dos trabalhos, contextos educacionais e focos temáticos. Pesquisa em Educação Ambiental, São Carlos, SP, Brasil, v. 4, n. 2, p. 147163, Jul./Dez. 2009.

MARIN, M.; OLIVEIRA, H. T.; COMAR, V. A Educação ambiental num contexto de complexidade do campo teórico da percepção. Interciência, Caracas, v. 28, n. 10, p. 616-619, 2003.

MONTANHIM, G. C.; CARON, M. F.; CINQUETTI, H. C. S. Aspectos linguísticos e Educação Ambiental na aprendizagem infantil. Pesquisa em Educação Ambiental, São Carlos, SP, Brasil, v. 6, n. 2, p. 11-32, Jul./Dez. 2011.

NETA, M. V. B; FONSECA, B. M. Projetos de Educação Ambiental de escolas públicas e particulares do Distrito Federal: uma análise comparativa. Pesquisa em Educação Ambiental, São Carlos, SP, Brasil, v. 7, n. 1, p. 85-100, Jan./Jun. 2012.

PÁDUA, S. M. A educação ambiental: um caminho possível para mudanças. In: VIANNA, L. P. (Coord.). Panorama da Educação Ambiental no Ensino Fundamental, Brasília: MEC; SEF, 2001. p. 77-81. (Oficina de trabalho realizada em março de 2000). Disponível em: <http://www.crmariocovas.sp.gov.br/pdf/pol/panorama_educacao.pdf >. Acesso em: 10 nov. 
2013.

PANZERI, C. G.; COMPIANI, M.; ALBERTO JR, L. Pensando a educação ambiental sob o enfoque didático de natureza socioconstrutivista: contribuições do Projeto Acre 2000 de Educação Ambiental. Pesquisa em Educação Ambiental, São Carlos, SP, Brasil, v. 5, n. 1, p. 141-169, Jan./Jun. 2010.

PESSOA, G. P., BRAGA, R. B. O trabalho de campo como estratégia de educação ambiental nas escolas: uma proposta para o ensino médio. Pesquisa em Educação Ambiental, São Carlos, SP, Brasil, v. 7, n. 1, p. 104-122, 2012.

REIGOTA, M. O Estado da Arte da Pesquisa em Educação Ambiental no Brasil. Pesquisa em Educação Ambiental, São Carlos, SP, Brasil, v. 2, n. 1, p. 33-66, Jan./Jun. 2007.

REIS, M. F. C. T.; TALAMONI, J. L. B; RUIZ, S. S.; NEVES, J. P.; REIXEIRA, L. A.; CASSINI, L. F.; FESTOZO, M. B; JANKE, N.; MAIS, J. S. S.; SANTOS, H. M. S.; CRUZ, L. G.; MUNHOZ, R. H. A educação ambiental na escola básica: diretrizes para a divulgação dos conhecimentos científicos. Pesquisa em Educação Ambiental, São Carlos, SP, Brasil, v. 7, n. 1, p. 29-48, Jan./Jun. 2012.

SANTOS, L. M. F.; MARTINS, I. Mapeamento do campo a partir de publicações em periódicos das áreas de Educação Ambiental, educação em ciências e educação no período de 1999 a 2006. In: ENCONTRO NACIONAL E PESQUISA EM EDUCAÇÃO EM CIÊNCIAS, 6, Florianópolis, 2007 Atas... Rio de Janeiro: UFRJ, 2007. s/p. disponível em <http://www.nutes.ufrj.br/abrapec/vienpec/autores0.html>, Acesso em 19 nov. 2015.

SANTOS, M. L.; BARBOSA, W. A.; CAON, K.G. Caminhos para a Permacultura Popular: experiência de formação do Grupo Sauipe - Saúde Integral em Permacultura. Ambiente \& Educação, Rio Grande, RS, Brasil, v. 17, n. 2, p. 117-132, 2012.

SATO, M.; GAUTHIER J. Z.; PARIGIPE, L. Insurgência do grupo pesquisador na educação ambiental sociopoética. In: SATO, M., CARVALHO, I. (Orgs.). Educação ambiental: pesquisa e desafios. Porto Alegre: Artmed, 2005, p.119-133.

SEGURA, D. S. B. Educação Ambiental na escola pública: da curiosidade ingênua à consciência crítica. São Paulo: Annablume, 2001.

SOUZA, P. P. S., PEREIRA J. L. G. Representação social de meio ambiente e educação ambiental nas escolas públicas de Teófilo Otoni-MG. Revista Brasileira de Educação Ambiental, Rio Grande, RS, Brasil, v. 6, n.1, p. 35-40, Abr. 2011.

TRAJBER, R.; MENDONÇA, P. R. Educação na diversidade: o que fazem as escolas que dizem que fazem educação ambiental. Brasília: Secretaria de Educação Continuada, Alfabetização e Diversidade, 2007. 